\title{
Measurement of Achilles Tendon Thickness is a Key for International Harmonization in Clinical Diagnosis of Familial Hypercholesterolemia
}

\author{
Shinji Yokoyama
}

Chubu University, Aichi, Japan

\section{See article vol. 28: 000-000}

Familial hypercholesterolemia $(\mathrm{FH})$ is one of the most common genetic diseases, appearing as high as 1 heterozygote in a general population of 300 individuals globally. This is caused by the diversity of the causing mutations in several genes related to LDL metabolism ${ }^{1,2)}$. Accordingly, it substantially impacts public health by causing atherosclerotic vascular illness, such as coronary heart disease (CAD). Screening patients with $\mathrm{FH}$ and their families early enough is therefore important to prevent cardiovascular complications, not only for saving their lives and improving their quality of life but also for relieving public health burden and saving social healthcare cost.

The Japan Atherosclerosis Society (JAS) proposed the guidelines for the diagnosis of FH (JASG) designed to identify patients with $\mathrm{FH}$ in general practice first in 2012 ${ }^{3}$ and its renewed version in $2017^{4)}$, where $\mathrm{FH}$ is defined by the presence of at least two of the three major symptoms of a high LDL cholesterol $(\geq 180 \mathrm{mg} / \mathrm{dl})$, a family history of $\mathrm{FH} /$ premature $\mathrm{CAD}$, and tendon/skin xanthomas defined as Achilles tendon thickness (ATT) $\geq 9 \mathrm{~mm}^{3,4)}$. To estimate the contribution of $\mathrm{FH}$ to cardiovascular diseases in Japan, Ohmura et al. found 5.7\% and 7.8\% by JASG in all age and under 60, respectively, among 359 Japanese patients with acute coronary symptom (ACS) from five major urban hospitals ${ }^{5)}$. Tanaka and his colleagues also demonstrated that FH by JASG accounted for $4.3 \%$ in all and $15.4 \%$ in those under 60 among 141 patients with ACS in a single community hospital ${ }^{6}$. Harada-Shiba et al. analyzed 1944 patients with ACS (mean age, 66.0 years; men, $80.3 \%)$ and found $52(2.7 \%)$ patients with $\mathrm{FH}^{7)}$. $\mathrm{FH}$ finding by JASG thus seems largely consistent throughout these studies. Accordingly, the estimated overall risk of ACS is 10 times high among $\mathrm{FH}$ in comparison to the general Japanese population and even higher among those under 60. The early commencement of their treatment could reduce premature CAD as much as $10 \%$ in Japan.

The Dutch Lipid Clinic Network Algorithm $(\mathrm{DLCNA})^{8)}$ is widely used for finding $\mathrm{FH}$ in the EU region and other parts of the world, based on scoring system for the level of certainty in diagnosis, by family and clinical history, LDL cholesterol, and the presence of skin/tendon xanthomas by physical examination. Xanthomas are defined left arbitrary for subjective recognition, and this may have caused some inconsistency among the studies by the DLCNA. It identified $1.6 \%$ and $4.8 \%$ of probable/definite $\mathrm{FH}$ among ACS in a Switzerland study ${ }^{9)}$ and $2.0 \%$ and $7.0 \%$ among those with first myocardial infarction in a Danish study in all age and those under 60, respectively ${ }^{10)}$. The EUROASPIRE study covering 7044 patients with coronary disease from 24 European countries found more definite/probable $\mathrm{FH}$ as $8.3 \%$ in all ages and $15.4 \%$ and $5.1 \%$ in those under and above $60^{11)}$. Similar reports from China demonstrated the contribution of $\mathrm{FH}$ to CAD by the DLCNA definite/probable criteria as $3.9 \%$ for all ages and $7.1 \%$ for those under $60^{12)}$. The higher prevalence of $\mathrm{FH}$ among younger patients with ACS is consistent throughout these reports, whereas diversity and inconsistency may be found in the rate of $\mathrm{FH}$ contribution to ACS. The parallel application of the DLCNA to Japanese cohorts tested for JASG yielded uncertain differential diagnosis of $\mathrm{FH}$, except for definite criteria ${ }^{6,13)}$. These findings revealed that the DLNCA-based diagnosis of FH greatly depends on the arbitrary finding of xanthomas to which a high point was given in the scoring system, whereas JASG is based on more objective and quantitative criteria of measuring ATT.

Tada and his colleagues reported in this issue of 
Journal of Atherosclerosis and Thrombosis their attempt to seek more efficient cutoff value for ATT for diagnostic guideline for $\mathrm{FH}^{14)}$. The data indicates that the best cutoff values of ATT, based on receiver operating characteristic analyses, were found to be lower than the currently recommended ones in 2017 JASG, i.e., $7.6 \mathrm{~mm}$ for male and $7.0 \mathrm{~mm}$ for female with sensitivities and specificities of 0.83 and 0.83 for male and 0.86 and 0.85 for female, respectively. The graphic data in Figures 5 and 6 of the said paper ${ }^{14)}$ indicate that ATT seems to be a function of age and age-integrated LDL cholesterol. This means that the cutoff value should also be a function of age and/or age-integrated LDL cholesterol to give better sensitivity/specificity balance than the fixed value independent of age. Thus, JASG can be updated for better sensitivity and specificity by seeking the optimum cutoff for each screening parameter. However, it would not be fully compatible with the DLCNA; therefore, direct international collaborative work may become difficult.

More effort is need for international harmonization and standardization among the guidelines for reliable international comparison of the contribution of $\mathrm{FH}$ to public health, especially between the DLCNA and JASG. The difference is present in the recognition of xanthomas. The DLCNA leaves it on the findings in physical examination and the given high point in their scoring system for diagnosis, whereas the JASG adopts ATT measurement as one of the three major symptoms. The latter is objective and quantitative but requires imaging technology, which may be criticized for cost and unnecessary overexposure to radiation. The former, on the other hand, is free and has no risk, although it is subjective, arbitrary, and just qualitative. Because of lifestyle difference, including dietary profile, the appearance of xanthomas may be partially masked among Japanese patients with $\mathrm{FH}$; therefore, more objective and quantitative parameter is required to screen them in Japan. The argument is also partially based on the difference in the healthcare systems, such as the cost, access, and regulation. Japanese people are benefited by their public healthcare system in which access to hospitals and outpatient clinics nationwide, where most of conventional medical examinations are widely available, including X-ray survey. Ultrasonogram examination is also becoming popular in many of those institutions, and the application of this technology to measure ATT is being developed ${ }^{15-17)}$, making it a possible good alternative to X-ray examination.

In general practice, the diagnosis of $\mathrm{FH}$ is not straightforward even with the existence of the currently proposed guidelines. Genetic analysis does not cover all, and its clinical feature is diverse. Family history information is very important but inevitably overlooked in general practice. The common use of statin also causes difficulty and confusion by masking the LDL cholesterol level of patients with FH. International collaboration is very important for establishing clinical and public health approaches to prevent their complications. Japanese clinical scientists are strongly advised to publish more information on FH using JASG to validate and reinforce the accurate and reliable nature of this guideline in diagnosing this hereditary disease.

\section{Acknowledgement}

The author is grateful to Health, Labor and Welfare Sciences Research Grant for Research on Rare and Intractable Diseases and to a Grant-in-Aid from MEXT 21K11586.

\section{Conflicts of Interest}

The author has no conflict of interest to declare related to this article.

\section{References}

1) Sturm AC, Knowles JW, Gidding SS, Ahmad ZS, Ahmed CD, Ballantyne CM, Baum SJ, Bourbon M, Carrié A, Cuchel M, de Ferranti SD, Defesche JC, Freiberger T, Hershberger RE, Hovingh GK, Karayan L, Kastelein JJP, Kindt I, Lane SR, Leigh SE, Linton MF, Mata P, Neal WA, Nordestgaard BG, Santos RD, Harada-Shiba M, Sijbrands EJ, Stitziel NO, Yamashita S, Wilemon KA, Ledbetter DH, Rader DJ: Clinical genetic testing for familial hypercholesterolemia: JACC scientific expert panel. J Am Coll Cardiol, 2018; 72: 662-680

2) Tada H, Hori M, Nomura A, Hosomichi $K$, Nohara $A$, Kawashiri M, Harada-Shiba M: A catalog of the pathogenic mutations of LDL receptor gene in Japanese familial hypercholesterolemia. J Clin Lipidol, 2020; 14: 346-351.e349

3) Harada-Shiba M, Arai H, Oikawa $S$, Ohta T, Okada $T$, Okamura T, Nohara A, Bujo H, Yokote K, Wakatsuki A, Ishibashi S, Yamashita S: Guidelines for the management of familial hypercholesterolemia. J Atheroscler Thromb, 2012; 19: 1043-1060

4) Harada-Shiba $M$, Arai $H$, Ishigaki $Y$, Ishibashi $S$, Okamura T, Ogura M, Dobashi K, Nohara A, Bujo H, Miyauchi K, Yamashita S, Yokote K: Guidelines for diagnosis and treatment of familial hypercholesterolemia 2017. J Atheroscler Thromb, 2018; 25: 751-770

5) Ohmura H, Fukushima Y, Mizuno A, Niwa K, Kobayashi Y, Ebina T, Kimura K, Ishibashi S, Daida H, Research Committee on Primary Hyperlipidemia of the Ministry of $\mathrm{H}$, Welfare of J: Estimated prevalence of heterozygous 
familial hypercholesterolemia in patients with acute coronary syndrome. Int Heart J, 2017; 58: 88-94

6) Tanaka N, Teramoto T, Yokoyama S: Application of the Japanese guidelines for the diagnosis of familial hypercholesterolemia in general practice: It is to be validated in international harmonization. J Atheroscler Thromb, 2019; 26: 93-98

7) Harada-Shiba M, Ako J, Arai H, Hirayama A, Murakami Y, Nohara A, Ozaki A, Uno K, Nakamura M: Prevalence of familial hypercholesterolemia in patients with acute coronary syndrome in Japan: Results of the EXPLORE-J study. Atherosclerosis, 2018; 277: 362-368

8) https://www.athero.org.au/fh/wp-content/uploads/ Dutch-Lipid-Clinic-Network-Score2.pdf

9) Nanchen D, Gencer B, Auer R, Raber L, Stefanini GG, Klingenberg R, Schmied CM, Cornuz J, Muller O, Vogt P, Juni P, Matter CM, Windecker S, Luscher TF, Mach F, Rodondi N: Prevalence and management of familial hypercholesterolaemia in patients with acute coronary syndromes. Eur Heart J, 2015; 36: 2438-2445

10) Mortensen MB, Kulenovic I, Klausen IC, Falk E: Familial hypercholesterolemia among unselected contemporary patients presenting with first myocardial infarction: Prevalence, risk factor burden, and impact on age at presentation. J Clin Lipidol, 2016; 10: 1145-1152.e1141

11) De Backer G, Besseling J, Chapman J, Hovingh GK, Kastelein JJ, Kotseva K, Ray K, Reiner Z, Wood D, De Bacquer D, Investigators E: Prevalence and management of familial hypercholesterolaemia in coronary patients: An analysis of EUROASPIRE IV, a study of the european society of cardiology. Atherosclerosis, 2015; 241: 169-175

12) Li S, Zhang Y, Zhu CG, Guo YL, Wu NQ, Gao Y, Qing P, Li XL, Sun J, Liu G, Dong Q, Xu RX, Cui CJ, Li JJ: Identification of familial hypercholesterolemia in patients with myocardial infarction: A Chinese cohort study. J Clin Lipidol, 2016; 10: 1344-1352

13) Tada H, Okada H, Nomura A, Usui S, Sakata K, Nohara A, Yamagishi M, Takamura M, Kawashiri M: Clinical diagnostic criteria of familial hypercholesterolemi - A comparison of the Japan Atherosclerosis Society and Dutch Lipid Clinic Network criteria. Circ J, 2020;

14) Tada H, Hori M, Matsuki K, Ogura M, Nohara A, Kawashiri M, Harada-Shiba M: Achilles tendon thickness assessed by X-ray predicting a pathogenic mutation in familial hypercholesterolemia gene. J Atheroscler Thromb, 2021; In Press. doi: http://doi.org/10.5551/jat.62869

15) Ebeling T, Farin P, Pyörälä K: Ultrasonography in the detection of Achilles tendon xanthomata in heterozygous familial hypercholesterolemia. Atherosclerosis, 1992; 97: 217-228

16) Descamps OS, Leysen X, Van Leuven F, Heller FR: The use of Achilles tendon ultrasonography for the diagnosis of familial hypercholesterolemia. Atherosclerosis, 2001; 157: 514-518

17) Michikura M, Ogura M, Yamamoto $M$, Sekimoto $M$, Fuke C, Hori M, Arai K, Kihara S, Hosoda K, Yanagi K, Harada-Shiba M: Achilles tendon ultrasonography for diagnosis of familial hypercholesterolemia among Japanese subjects. Circ J, 2017; 81: 1879-1885 